\title{
A systematic review of strategies to recruit and retain primary care doctors
}

\author{
Puja Verma', John A. Ford ${ }^{1 *}$, Arabella Stuart ${ }^{1}$, Amanda Howe${ }^{1}$, Sam Everington ${ }^{2}$ and Nicholas Steel $^{1}$
}

\begin{abstract}
Background: There is a workforce crisis in primary care. Previous research has looked at the reasons underlying recruitment and retention problems, but little research has looked at what works to improve recruitment and retention. The aim of this systematic review is to evaluate interventions and strategies used to recruit and retain primary care doctors internationally.

Methods: A systematic review was undertaken. MEDLINE, EMBASE, CENTRAL and grey literature were searched from inception to January 2015. Articles assessing interventions aimed at recruiting or retaining doctors in high income countries, applicable to primary care doctors were included. No restrictions on language or year of publication. The first author screened all titles and abstracts and a second author screened $20 \%$. Data extraction was carried out by one author and checked by a second. Meta-analysis was not possible due to heterogeneity.

Results: Fifty-one studies assessing 42 interventions were retrieved. Interventions were categorised into thirteen groups: financial incentives $(n=11)$, recruiting rural students $(n=6)$, international recruitment $(n=4)$, rural or primary care focused undergraduate placements $(n=3)$, rural or underserved postgraduate training $(n=3)$, wellbeing or peer support initiatives $(n=3)$, marketing $(n=2)$, mixed interventions $(n=5)$, support for professional development or research $(n=5)$, retainer schemes $(n=4)$, re-entry schemes $(n=1)$, specialised recruiters or case managers $(n=2)$ and delayed partnerships $(n=2)$.

Studies were of low methodological quality with no RCTs and only 15 studies with a comparison group. Weak evidence supported the use of postgraduate placements in underserved areas, undergraduate rural placements and recruiting students to medical school from rural areas. There was mixed evidence about financial incentives. A marketing campaign was associated with lower recruitment.

Conclusions: This is the first systematic review of interventions to improve recruitment and retention of primary care doctors. Although the evidence base for recruiting and care doctors is weak and more high quality research is needed, this review found evidence to support undergraduate and postgraduate placements in underserved areas, and selective recruitment of medical students. Other initiatives covered may have potential to improve recruitment and retention of primary care practitioners, but their effectiveness has not been established.
\end{abstract}

Keywords: Primary care, Recruitment, Retention, Workforce, Systematic review

\section{Background}

The World Health Organisation (WHO) describes a Global Health Workforce Crisis [1,2] with many low and high income counties experiencing difficulty recruiting and retaining doctors in rural and underserved areas [2]. The WHO has described how increased availability of healthcare workers in these areas is crucial to

\footnotetext{
* Correspondence: John.Ford@uea.ac.uk

${ }^{1}$ Faculty of Medicine and Health Sciences, Norwich Medical School,

University of East Anglia, Chancellors Drive, Norwich NR4 7TJ, UK

Full list of author information is available at the end of the article
}

population health [1]. The reasons behind the workforce crisis are multifactorial but aging and expanding populations and new health challenges mean that access to good quality primary care is now more important than ever [3]. In the United Kingdom (UK) the General Practice (GP) workforce crisis is having a direct effect on patient care, deprived and rural areas are particular vulnerable [4]. There are insufficient doctors to meet demands consequently up to $543 \mathrm{GP}$ practices could be forced to close within the next year [5]. The Royal College of General Practitioners (RCGP) 
estimated that 8000 more GPs are needed by 2020 [5] leading to the introduction of a UK target of $50 \%$ of foundation trainees entering general practice by 2016 [6]. In the mid1980 s, general practice was the most popular career choice for medical students [7], but more recently it has become less popular than hospital medicine, with some students using it as a 'failsafe' or 'backup' career choice [8] with national applications for GP training decreasing by $6.2 \%$ in 2015 than in the previous year [9].

Morale amongst practising primary care doctors is lower than in any other medical speciality and more are facing burnout and stress due to increasing workload and limited resources [10]. For example, in the UK $30 \%$ of all GPs intend to leave direct patient care in the next five years [11]. The demand for part-time or flexible working patterns has increased, partly due to the increasing number of female medical practitioners, and partly due to changing expectations of both men and women [12]. Many high income countries have traditionally relied on international medical graduates (IMGs) to fill vacancies, but that is no longer possible. Despite more European-trained doctors working in the UK, the overall number of IMGs has dropped. The number of newly registered Indian doctors fell from 3640 in 2004 to 340 in 2013 [13], and 16\% of overseas-qualified (outside of the European Economic Area) GPs are expected to retire over the next five to ten years [14].

Many international policies have attempted to address the problem of primary care doctor recruitment and retention $[4,15]$, and it is clear from other countries that significant change in a sector of a health service "requires a solid blueprint, pilot testing and evidence generation, a long-term vision, and sustained financial and political commitments"[16]. The international literature also demonstrates that it may be necessary to change the business model and professional culture in order to stabilise workforce and improve morale [17]. In the UK, $£ 10$ million has been committed by NHS England to implement a strategic ten point GP workforce action plan in 2015 in the UK [15]. Its three main areas for improvement are in recruitment, retention, and support for returning doctors. The recruitment initiative includes marketing campaign and recruitment video [18], a letter to all medical school graduates describing the positive aspects of a future career in general practice, and an additional year post training to recruit trainees to underserved areas. The report describes a three year scheme to offer financial incentives to trainees working in underserved areas. Furthermore, pilot 'training hubs' will offer inter-professional training to primary care staff, developing and extending the current skills base. The retention initiative includes retainer schemes and improved training capacity in general practice. Experienced GPs towards the end of their careers will be offered incentives to remain in practice, and opportunities to develop a portfolio career. Innovative ways to manage GP workload are proposed such as using physician associates, medical assistants, clinical pharmacists, and other allied health professions. A new Health Education England induction and refresher scheme aims to support GPs who have previously practiced to return to the workforce [19].

Little research has assessed the effectiveness of recruitment and retention policies for primary care doctors. The aim of this systematic review is to evaluate interventions and strategies used to recruit and retain primary care doctors internationally.

\section{Methods}

Electronic searches of MEDLINE, EMBASE, and CENTRAL were conducted from inception to January 2015. Search terms (in English) used in MEDLINE are shown in Appendix 1. The search strategy included MESH and free text terms in three areas: 1) primary care, 2 ) recruitment and retention and 3) study design. Grey literature searches were undertaken in OpenSigle, internet search engines (Google and Google Scholar) and targeted websites (RCGP, Kings Fund, Health Education England, British Medical Association and specific international websites such as The Australian Government Department of Health and The World Health Organization). Specific organisations were contacted for unpublished evaluations such as Health Education England, British Medical Association and UK Local Education and Training Boards. Reference lists of the included studies and reviews were screened.

\section{Inclusion and exclusion criteria}

To meet the inclusion criteria, studies were required to evaluate a defined intervention aimed at recruiting or retaining doctors. Studies that included medical specialities, other than primary care were included if judged to be transferable to primary care by the three authors (PV, NS and JF). Only articles from high income countries (as defined by the Organisation for Economic Co-operation and Development) were included, as the issues and strategies for low and middle income countries were very different and were mainly focused on medical migration. There was no limit on study design, language or followup period. Studies of other health professionals, such as nurses, were excluded. All studies without a specific intervention were excluded,

\section{Screening and data extraction}

Titles and abstracts were screened by one reviewer (PV) and a second reviewer (JF) screened $20 \%$ of the total sample retrieved from the search strategy to check for concordance and to minimize bias. Unclear studies were resolved through a three way discussion (PV, NS, JF). 
Data extracted included study details, inclusion/exclusion criteria, study design, intervention specification costs and outcome measure. Data were extracted by one author (PV) and double checked by a second (AS).

The primary outcome was number of primary care doctors recruited or retained. Secondary outcomes were recorded when available in the included studies, these were average duration of employment after recruitment, future intentions and cost. Authors were contacted for supplementary data if necessary. The risk of bias of each study was assessed by two reviewers (PV and AS) using the Newcastle Ottowa Scale, which was modified to meet the needs of the included studies to include presence of a comparison group, generalisability, conflicts of interest and quality of reporting [20]. Studies were considered for meta-analysis, but were judged to be too heterogeneous.

\section{Results}

Three thousand five hundred ninety seven reports were identified from the electronic search (2753 after removal of duplicates) (Fig. 1) plus 28 from the grey literature search. After screening and eligibility assessment, 51 studies were included, describing 42 interventions. Seventeen studies were from the USA, twelve from the UK, eight from Australia, five from Canada, four from Norway, two from both Japan and New Zealand and one from Chile (Table 1).

The length of follow up ranged from one to 32 years. The number of participants included in the studies ranged from 7 to 2988. Sample sizes were generally small and 7 studies had less than 20 participants. In 8 studies the outcome was the self-reported location where the trainee or doctor was practicing after the intervention. Some studies used national databases or practice address as the outcome measure.

There were no randomised control trials (RCTs). 38 used a cross-sectional design, of which 30 did not include a comparison group, and 8 had a betweengroup comparison. Thirteen studies were a longitudinal design, of which six lacked a comparison group. Of the seven longitudinal comparison studies, one

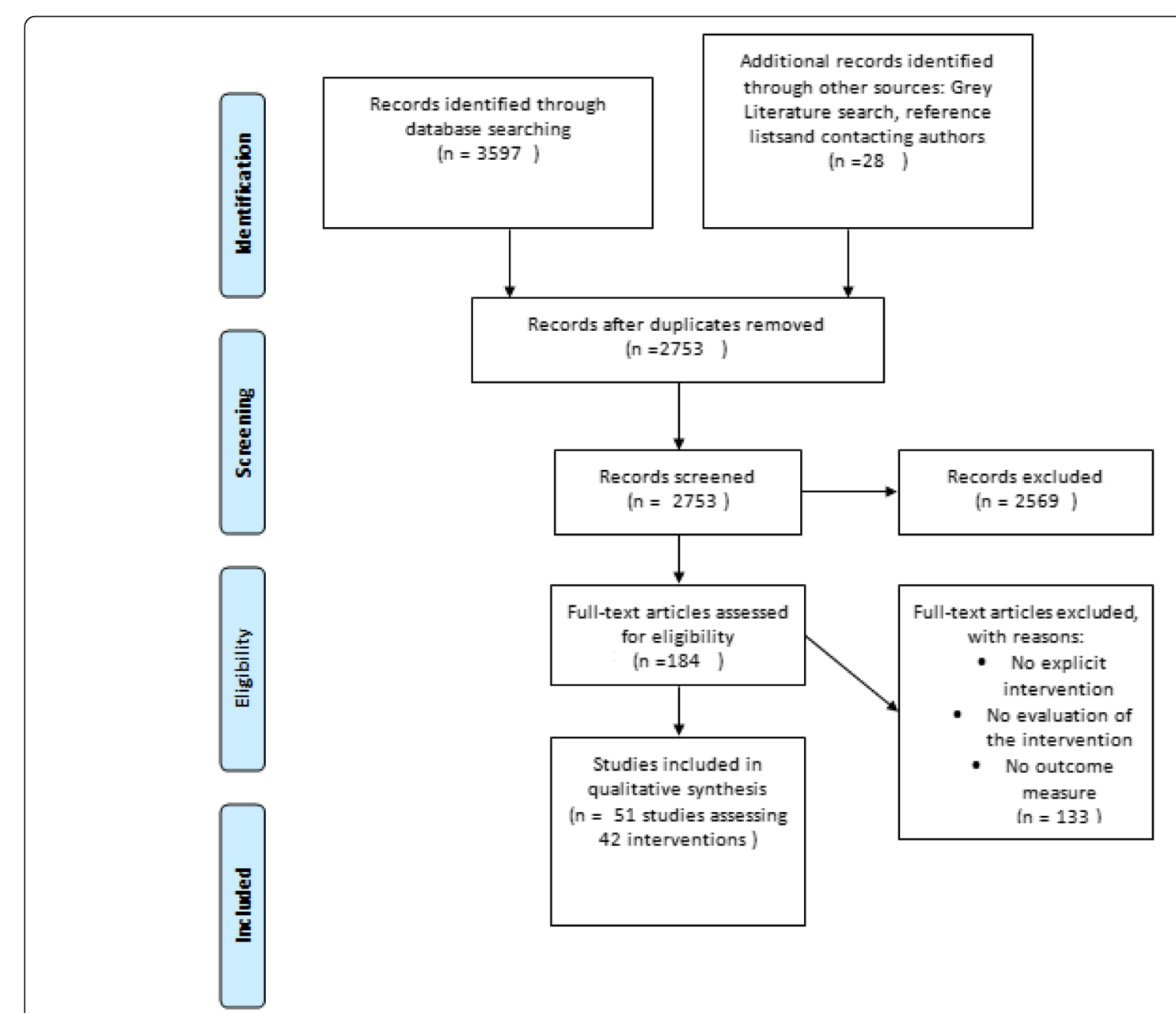

Fig. 1 PRISMA Diagram 
Table 1 Description of intervention, costing and outcomes

2 US department of Health and Human Services: The National Health Service Corps (NHSC) (2012) [23] (Webpage) USA Health Service Corps and Other Rural Physicians Results of a 9 year follow up study Pathman (1992) [24] USA

The National Health Service Corps: Rural Physician Service and retention Cullen et al. (1997) [25]

USA
The Comparative Retention of Nationa

Longitudinal follow up comparative between groups $=2988$

Longitudinal follow up comparative between groups $n=1255$

Long term effect of the Home

Jichi Medical

Matsumoto et al. (2008) [22]

apan

Longitudinal follow up non comparative

$n=$ not

reported

ongitudinal follow up

comparative between groups $n=304$

Cross sectional - non

comparative

$n=2903$

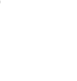

Description of intervention (year)

Costs

Aims to recruit rural doctors and distribute them nation-wide. Jichi Medical University (1972onwards) mission to produce rural

scheme". 9 year obligation service, 6

of those in rural practice after

graduating - in their home

prefecture. In exchange all

undergraduate fees are waived.

The National Health Service Corps

(NHSC) (1970 onwards)

3 financial incentives: Loan

Repayment: Up to

$\$ 50,000$ to repay their health

profession student loans in exchange for a two-year commitment to work at an approved NHSC site in a highneed, underserved area. Scholarships: pays tuition

fees, other educational costs, and

provides a living stipend in return for a commitment to work at least 2 years at an approved

outpatient facility in a medically

underserved community. The

scholarship can be awarded for up

4 years. Service begins upon

graduation. Students to Service Pro-

gram Loan Repayment Program

(S2S LRP) provides up to $\$ 120,000$ to

medical students in their final year of

school in return for a commitment to

provide primary health

care full time for at least 3 years at an

approved NHSC site in a Health

Professional Shortage Area of

greatest need. NB length of

obligations changed throughout the

program history
If in breach of contract - all medical school expenses must be repaid in a lump sum
(US $\$ 183,333)$, plus $10 \%$ per year in interest.

Loan repayment up to $\$ 50,000$

Bond of $\$ 120,000$

.


Table 1 Description of intervention, costing and outcomes (Continued)

3 Voluntary Bonding Scheme

New Zealand Ministry of

Health (2012) [26] (webpage)

New Zealand

Cross sectional

non comparative

$n=115$

4 Postgraduate medical placements in rural areas: their impact on the rural medical workforce. Dunbabin (2006) [27] Australia

5 A Comparative assessment of West Virginias Financial Incentive Programs for Rural Physicians Jackson et al. (2003) [28] USA
Longitudinal follow up non comparative $n=82$

Cross Sectional -

comparative between groups $n=251$
For postgraduate doctors intending to train as GPs (2009- present) or allied health professionals who are prepared to train in rural or provincial area can enter the scheme when they enter vocational training. Incentive scheme with no upfront bonding agreement to sign - after being accepted you begin working or continue to work in an eligible hard to staif community specialty terms and conditions of your intake terms and conditions of your intake eligible to apply for payments after year 3, 4 and 5 years. $\$ 10,000$ annua after tax payment for up to 5 years.

Cadetship Program (1988 onwards) offering bonded scholarships to provide financial support for medical students (residents of NSW and from 2005 the Australian Capital territory) during their final 2 years of

undergraduate study. In return cadets are contracted to complete 2 of their first 3 postgraduate years in the NSW rural hospital network.

West Virginias 4x financial incentive programs (1991 onwards): Community Scholarship Program (CSP) Average scholarship $=\$ 42,500$ for students from a Health professional shortage area (HPSA) to commit to go back and serve 1 year for every year of funding received back in their home HPSA.

Health Science Scholarship Program

(HSSP) for fourth year medical students. $\$ 20,000$ one-time award for a minimum of 2 years' service in an underserved area. Recruitment and Retention Community Project (RRCP) : for medical residents up to $\$ 20,000$ each year for up to 6 years

(one year service required for each year of funding).

State loan repayment program for physicians up to $\$ 40,000$ for 2 year commitment contract (may be extended for 2 additional years at $\$ 25,000$ a year), for minimum 2 years' service at a non-profit site in a HPSA. Must repay the funding back in full if they default.

Incentive of $\$ 10,000$

In 2009115 doctors entered.

- By 2012102 (89\%) had opted out of the scheme.

- In a survey of the 2009 cohort showed 9/37 (35\%); stated they planned to work in a hard to staff location in both the short and long term. - Significant attrition; no penalty for opting out

Bond amount not reported

See individual programme $n=14$ (32\%) of all obligated physicians reported that they were no longer at their first service rural practice site compared to $n=41(38 \%)$ of the comparison group. (Similar retention patterns).

- Obligated physicians who remained in their initial rural practice anticipated to remain an average of 18 more years in rural practice. Nonobligated physicians had similar expectations. - $6 / 14$ (42\%) of the obligated respondents left their practice for another West Virginia rural site compared to $34 / 41$ (82 \%) of the

comparison group

before 1999 were working in rural location practitioners nationally)

17/22 (77\%) GPs were in a practice location rural service.

$44 \%$ had chosen to specialise in GP and $44 \%$ had chosen to specialise in GP and
made up $70 \%$ of those working in rural areas in 2004 
Table 1 Description of intervention, costing and outcomes (Continued)

6 Evaluation of Physician Return

for service Agreement in

Newfoundland and Labrador

Mathews et al. (2013) [29]

USA

7 Evaluation of the Arizona Medical student Exchange Program. Navin TR and Nichols AW (1977) [30] USA
Longitudinal follow

up comparative between

groups

$n=134$

Cross sectional -

non comparative

$n=$ unclear
Special funded residency positions administered by Memorial University of Newfoundland-(1997-2006) Offers funding to medical students and to postgraduate residents training in family medicine and other specialis programmes in which physician shortages were identified (the funding is gained in return for service).

A Family Medicine bursary is also available to $3^{\text {rd }}$ and $4^{\text {th }}$ year medical students intending to pursue family medicine

Those who accept the funding are expected to work in Newfoundland for 1 year for each year of funding received. They can also pay the money back (with interest).

Students from 11 states which lack training facilities are given financial assistance to attend graduate

programs in the health sciences.(1969onwards) The cost that an Arizona student faces in attending an out of state medical school is covered $(\$ 500$ in 1953) for return of service to Arizona: 2 years' service for every year of participation in the program. (Reduced to 1:1 years in 1958 due to low uptake) The accepting school is also offered an 'additional sum' of $\$ 6000$ as an inducement to accept more Arizona students in the future. The students were given the option to repay the debt in cash

Cross sectional -

comparative between groups $n=1157$

Not reported

Retention of Return For Service vs Non Return For Service physicians who first started practice between 2000 and 2005

- 11/60 (19 \%) of Return For Service graduates had left the province, compared to 28/67 (42\%) of non-Return For Service graduates - RFS physicians were 3.2 times less likely compared to Non Return For Service physicians to leave the province.

8 Outcomes of states' scholarship loan repayment, and related programs for physicians Pathm
5 Program types which were operating in 1996 (onwards) were compared :

Scholarships- obligate medical students early in their training many years before they serve their

obligations, firmly expected to provide service, hefty penalties are used to discourage them from buying out of the obligation
Sending state paid receiving school $\$ 6000$
Not reported

1953 the first medical students were

assisted by the program:

- From 1953 to 1967 the program failed to the raise the number of medical school

applications from Arizona.

- Between 1955 and 1965 there was a

consistent decline in the physician-

population ratio (NB time lag whilst students are at medical school)

Out of 149 program graduates

-21/149 (14 \%) chose service repayment in a rural area within Arizona.

Out of the 143 who have started discharging their obligation

. 55/143 (38 \%) chose cash repayment instead of service.

-67/143 (47 \%) chose service in a metropolitan area within Arizona

As of 1975

- $62 \%$ of participants repaid there loan

obligation through service in the state- but

not specifically to rural areas.

Obligated physicians remained longer in their Practices than non-obligated physicians

$(p=0.03) 71 \%$ vs $61 \%$ at 4 years and $55 \%$ vs $52 \%$ at 8 years

- Obligated physicians worked in underserved areas (low physician to population ratio) more often than non-obligated physicians $37 \%$ vs $11 \% p<0.001$

- Obligated physicians remained longer in their service practices than non-obligated physicians 
Table 1 Description of intervention, costing and outcomes (Continued)

Service option loans- targeted to medical students - can perform service or repay the loans at standard interest rates

Loan repayment - commit physician later, nearing the end of residency. Provide assistance to repay loans accrued earlier in medical school. Minimal penalties on physicians who fail to provide a period of service. Direct financial incentives: "golden hello" to work in rural area; usually no penalty or minimal penalty for failure to complete minimal service. Resident support - financial assistance; scholarships, loan repayment and direct financial incentive- service begins 1-2 years after commitment at the end of residency.

Recruit rural students

9 Long Term Retention of Graduates from a program to increase the Supply of rural Family Physicians Rabinowitz (2005) [32] USA

10 The Contribution of Memoria University's medical school to rural physician supply Mathews (2008) [33] Canad

11 Influencing residency choice and practice location through a longitudinal rural pipeline program

Quinn (2011) [34]

USA
Cross sectional comparative between groups $n=1937$ non comparative $n=1322$
The Physician Shortage Area Programme (PSAP) (1974 onwards). Recruited applicants with a rural background, eligible for financial aid (payable loans). Undertake rural family medicine placements in rural areas in their $3^{\text {rd }}$ and $4^{\text {th }}$ years.

Long standing 'med quest' program (1973 onwards) to encourage secondary school students to a heath professional career. More than $30 \%$ of memorial medical students are from rural origin compared with $1 \%$ of other Canadian medical schools Medical school tuition is half the Canadian average

Cross sectional non comparative $n=1046$
The Missouri University Rural Track Pipeline Program (MU RTPP) (1995 onwards) has a preadmission program for rural students (rura scholars). Summer community programs for second year students: students participate in a clinical program in a rural community setting; participating hospital or clinic in their first jobs after training ( $\mathrm{HR}$ for leaving $0.70 ; 95 \% \mathrm{Cl} 0.51-0.96 P=0.029$ )

- Longest group retention was seen for

ban repayment scheme $66 \%$ of whom

remained in their service sites for 8 years. - Service option loans reported the lowest average service completion rate (44.7\%) - Scholarship programs had a service completion rate of (66.5\%)

- The highest buy out rate was for service option loan programs (49.2 \%) and scholarship program $(27.2 \%)$
Not reported

Not reported

(n) 1978-1986 (148 PSAP graduates) 38 PSAP graduates identified.

- After 11-16 years 26/38 (68\%) PSAP graduates were still practicing family medicine in the

same rural area compared to 25/54 (46 \%) of their non-programme peers $(p=0.03)$ in 2002

Practice locations in 2004 were determined for graduates from 1973 to 1998. - In 2004 81/1322 (6.1 \%) of graduates were working in a rural community in Newfoundland making up (20.8\%) of the rural physicians in the province.

- $n=167$ (12.6\%) graduates worked in Rural Canada making up $4.9 \%$ of the rural physicians in Canada.

- Predictors of primary care doctors working in the area included having a rural background (OR 2.52 $95 \% \mathrm{Cl}$ 1.72-3.71) being from the area (OR 5.90, 95 \% 1.80-19.36).

48 rural scholars were tracked from 2002 and compared to non-participants and RTC participants

- 18/20 (90 \%) of rural scholars are practicing in Missouri

- 37/75 (49.3\%) of RTC are practicing in Missouri. - $57.4 \%$ of students who participated in the RTC program chose a rural location for their first practice
Not reported 
Table 1 Description of intervention, costing and outcomes (Continued)

sponsors students and the student

receives a stipend $(\$ 1000-\$ 2000)$.

Aim to increase knowledge of rura

medicine, improve clinical skills

Six month Rural Track Clerkship (RTC)

for third year medical students:

students live and work in a rural

community

Rural track elective for 4th year

medical students- one month

primary care or specialty electives in

a rural setting

12 Improving the recruitment and retention of doctors by training medical students locally

Landry et al. (2011) [35]

Canada

13 Rural doctor recruitment: does medical education in rural districts recruit doctors to rural areas?

Magnus et al. (1993) [36]

Norway

14 Illinois RMED: A Comprehensive Program to Improve the Supply of Rural Family Physicians Stearns et al. (2000) [37]

$$
\text { USA }
$$

\section{International recruitment}

15 From Spain to County Durham: experience of cross cultural genera practice recruitment Bregazzi et al.(2005) [38]

Cross sectional non comparative

$n=390$

Cross sectional

non comparative

$n=417$

Cross sectional non

comparative

$n=39$

$$
\text { UK }
$$

New Brunswick does not have

medical school. It's the only Canadian

bilingual province. Places reserved for

New Brunswick (NB) residents in

three French medical schools in

Quebec since 1967 students may also undertake part of their training in

their home province, and opportunity

to study in first language within

home province provided since 2006

Established a medical school in northern Norway (1972) with the

hypothesis of 'homecoming salmon.'

Educating young people from the

rural areas of northern Norway are

likely to stay in these remote areas.

Rural Medical Education (RMED)

(1993 onwards): Iongitudinal, multi-

dimensional program with a focus on family practice.

RMED provides a focused curriculum

for 4 years focusing on family

medicine, rural health issues and

community based medicine peer

support, a 16 week rural preceptorship.

Students recruited - must demonstrate

an orientation towards rural practice

and family practice Students sign a

pledge promising to complete the

4 year rural curriculum (no obligation/)

'The Durham Initiative' Spanish General Not reported Practitioners (2002-2003) were

recruited to under-doctored areas in

Durham. They undertook a 4 month

induction program of language

Not reported

Not reported

- Rural Scholars more than twice as likely to 'match' into family medicine

Of the 7 GPs recruited (1 dropped out part way through the year)

(71 \%) have continued to work

beyond the initial years contract
Questionnaire sent to all graduates from 1979 to 1989

234/417 (56.1\%) of The University of

Tromso graduates are retained in

Northern Norway.

• $n=192$ (82\%) of these doctors were

After 6 years 39 physicians have graduated - 27/39 (69 \%) of RMED alumni are in family practice residencies

. $32 / 39(82 \%)$ are working in primary care 
Table 1 Description of intervention, costing and outcomes (Continued)

training, supervised learning in the GP

training environment After induction

they began their first post, continuing

to meet weekly for peer group

sessions facilitated by a GP trainer +

Spanish born GP.

6 Retention of J1 Visa Waiver Program physicians in Washington States Health Professional Shortage Areas. Kahn et al. (2010) [39]

USA

The Effect of the Physician

J-1 Visa Waiver on Rural Wisconsin

Crouse (2006) [40]

USA

17 Choice or chance! The influence of decentralized training on GP retention in the Bogong region of Victoria and New South Wales Robinson et al. (2013) [41] Australia

Rural/primary care focused placements for undergraduates

18 Recruitment and retention of rural physicians: outcomes from the rural physician associate program of Minnesota Halaas et al. (2008) [42] USA
Cross sectional non comparative $n=141$

Cross sectional -

comparative between

groups

$n=145$

Conrad J-1 Visa Waiver Program:

(1994 onwards) International medica graduates can agree to serve in an officially designated rural or urban underserved area in an exchange for a J-1 visa waiver; removing the usual commitment to leave the United States for a minimum of two years on completion of training.

The doctors on this program are obligated to work for an approved

(in Washington $=3$ years)

J-1 Visa Waiver in Rural Wisconsin (1996 onwards)

As above and commitment period

(3 years).

Cross sectional non comparative $n=6$ non comparative $n=1175$ J-1 waiver employer for the duration of their commitment period
Decentralization of GP training

(1998 onwards) to regional training providers to attract Australian born GPs + IMG's to rural areas. Moratorium introduced in 1997 which allowed IMG and overseas born Australian trained doctor's access to a Medicare provider number \& access to government funded rebates if they trained in an accredited GP training program and practiced in 'areas of need' for up to 10 years. Regional training providers train GP registrars.

Rural Physician Associate Programme (RPAP)(1971 onwards)

$3^{\mathrm{RD}}$ year medical students assigned to rural communities for 9 month Hands on participation, one-one teaching, online curriculum participate in online discussion with fellow students meet with RPAP faculty 6 times/9 months.

- 3/7 (43\%) expect to continuing practice for between 1 and 3 years

Not reported Not reported 
Table 1 Description of intervention, costing and outcomes (Continued)

19 An Evaluation of the Rural Education program of the state university of New York Upstate Medical University 1990-2003

Smucny (2005) [43]

$$
\text { USA }
$$

20 Geographic and Speciality Distributions of WAMI program Participants and Nonparticipants Adkins et al. (1987) [44]$$
\text { USA }
$$

Rural/underserved postgraduate placement

21 Where are they Now

The Career paths of Remote

Vocational training scheme

registrars

Wearne (2010) [46]

Australia
Cross sectional -

groups

$n=2101$

Cross sectional

comparative between

groups

$n=2704$

Cross sectional -non

comparative

$n=24$

-64\% of all graduates practice in Minnesota and $36 \%$ in rural areas of the state

-160/410 (40 \%) graduates raised in

metropolitan areas currently practice within rural area.

- 1/2 of the RPAP class spend 2 years of medical school on a campus which actively recruits from a rural background

-896/1175 (82\%) of RPAP graduates have

chosen primary care 742/1175 (68.1\%)

family medicine

Voluntary. 36 week clinical experience in rural communities for medica students that began in 1989.

Until 2001 they also received a

$\$ 10,000$ stipend for participating in

RMED. Clinical training is completed

in rural communities

WAMI Program (1975 onwards) The states of, Alaska, Montana and Idaho, which lack training facilities entered

into a cooperative medical education

program- with The University of

Washington. It would accept 20

students each from Montana and

Idaho and 10 from Alaska each year.

It has a decentralized medical

school program where teaching

occurs in rural areas.

The remote vocational- training scheme (1999-2005) trains doctors in remote

communities using distance education

and supervision. Standard program was 3 years duration. Contact with

supervisors is minimal (a minimum of

$1 \mathrm{~h}$ per week in the first 6 months, $1 \mathrm{~h}$

per fortnight in the second 6 months,

and $1 \mathrm{~h}$ per month thereafter using

telephone, text, fax, email or internet

videoconferencing). Registrars attend

weekly tele-tutorials and develop their

clinical and procedural skills needed for the extended scope of remote clinical

practice at 2 yearly face to face

workshops
Until 2001 received a \$10,000 Between 1989 and 2003; 130 students have completed RMED:

. 22/86 (26\%) of RMED programme graduates (excluding residents) practiced in rural locations vs non programme students 95/ $1307(7 \%)[p<0.0001]$

-64/76 $84 \%$ believed RMED was important in helping them choose ?A3B2 show

$\$ 10 \#$ ? >location

In 1982 the programm cost the 4 states $\$ 4.8$

million collectively.

Graduates from 1975 to 1981 included: In 1984:

- $n=156 / 677$ (23\%) of graduates with programme experience were working in a non-metropolitan area compared to $n=32 / 260(12 \%)$ of graduates without programme experience.

Not reported

- 24 doctors graduated from the training scheme

- 6 graduates (25\%) work in the same location as they trained.

- $17 / 21$ (81\%) in rural areas

. $20 / 21$ (95\%) still work in Australia 
Table 1 Description of intervention, costing and outcomes (Continued)

22 Experiences of female General practice registrars: are Rural attachments encouraging them to stay?

Charles et al. (2005) [45] Australia

23 Training family physicians in community health centres: a health workforce solution Morris et al. (2008) [48] USA

Cross sectional - non comparative $n=83$

Cross sectional -

comparative between group $n=1312$

Well-being/peer support initiatives

24 Impact of support initiatives on retaining rural general practitioners

Gardiner et al. (2006) [48] Australia

25 Postgraduate training at the ends of the earth - a way to retain physicians?

Straume et al. (2010) [50]

Norway

Internship at the ends of the earth - a way to recruit physicians?

Straume et al. (2010) [49]

Norway

Marketing

26 The Effects of Video Advertising on Physician Recruitment to a Family Practice Residency Program

Longitudinal Study

comparative

(before and after)

$n=221$

ongitudinal study non comparative

$n=36$

Cross sectional -

comparative between

group

$n=233$
Mandatory minimum of 6 months

training in a rural area for GP

registrars on the General Practice

Education and Training Program

(2002)

21/65 (32\%) of registrars reported being more likely to work in a rural area as a direct result of the attachment

- 9/65 (14\%) were influenced against it as

a direct result of the attachment.

- Plans to work in a rural area were

positively associated with prior rural residence - Registrars on specific rural pathway training

had more intention of working in a rural

location after graduation $49 \%$ compared to

$22 \%$ of general pathway registrars $(p<0.05)$

R's for current practice in underserved area based on training exposure:

Community health care centres (1980 Not reported

onwards) federally funded primary

care clinics that provide care for

underinsured and uninsured patients

trained family medicine graduates-

with the hope that they will be

better prepared and more likely to

meet the health workforce demands

The DR DOC programme introduced

in 1999 (onwards) as a rural

workforce support programme

offering both social and emotional

support strategies as well as practica

interventions to help improve

primary care doctors health

and wellbeing including peer

supported networks, emergency

support lines and rural retreats, and

health check-ups for rural doctors and their families.

Special tutorial group started in

1997 (onwards) for postgraduates serving a 18 month medical

internship in rural area (normal in

Norwegian training program) to

enhance retention, decrease

professional and social isolation
Not reported OR 27 (95\% Cl 1.64.7) compare to non-

programme trained physicians

- $63.9 \%$ of CHC trained physicians working in underserved area compared to $37.3 \%$ nonprogramme physicians.

Followed up in 2001 (time 1) and 2003 (time 3) - Moderate reduction of $5 \%$ of those

considering on leaving rural General Practice after the Course

"Time 1": 98/187 (52.7\%) to "Time 2" : 102/221 $(46.1 \%)$

Not reported

29/36 (80 \%) family doctors were still working in Finnmark In 2003/4, 6 years after

completing their tutorial.

- Overall 5 year retention rate of $65 \%$

- Interns bought up in the north were 8 times more likely to take their first job in the north as those from a southern background (C1 2.2-29.6)

- Interns who graduated from the University of Tromso were 3.6 times more likely to take a job in the north than their counterparts from the southern universities.

20 people received the video

- 35 (29\%) of those who received the video completed the application process
- Family physicians training in a programme 
Table 1 Description of intervention, costing and outcomes (Continued)

between group
$n=248$

27 The Effect of a Blog on Recruitment to GPST in the north of Scotland Green (2015) [52]

UK

Mixed approach

28 Recruiting and Retaining GP's to remote areas in Northern The Senja Doctor Project. Conference presentation (2010) [53] Norway

29 The Chilean Rural Practitioner Programme: a multidimensiona strategy to attract and retain doctors in rural areas Pena (2010) [54] Bulletin of the World Health Organization Chile

Cross sectional non comparative $n=$ unclear

Cross sectional non comparative $n=$ unclear $n=$ unclear highlighted intellectual challenges/ scope of family practice. The video was sent to half of all persons inquiring about the residency programme. The remaining inquiries received all standard application materials and the residency brochure but not the video tape.

Online Blog (2012-2013) static pages and a dynamic blog section to feed information on GP training programme in the north of Scotland.

Five existing GP trainees blogged about their experiences of GP training in the north of Scotland. Newly qualified GPs wrote articles describing their time in training and subsequent careers- to demonstrate the variety of career paths in GP.

Project aimed to develop a collaborative model for GP services in the four Senja Municipalities (20072009). Establish a new main GP office where all doctors meet one a week. All doctors part of a professional network with a fixed wage

Driving to local offices included in working time, organized scientific activity, no public health responsibilities and continued medical education programs

Longitudinal follow up non comparative

The Rural practitioner Programme launched in 1955; four domains of incentives and a competitive application process

Education - voluntary rural clerkship4 week clerkship with physicians from the RPP

Financial - direct and indirect

incentives; direct = salary + tuition fees paid for increments full time compensation of $23 \%$, indirect e.g. installation and departure kit double salary for $1^{\text {st }}$ and last month transport tickets and a removal van compared to 69 (54\%) who did not receive the video

Controls (applicants who did not receive - Controls (applicants who did not receive Cl 1.6- 5.0) to apply to the programme $\mathrm{Cl} 1.6-5.0)$
$(p<0.0001)$

- After interview 0 of the 120 persons who received the video matched with the residency program $(p<0.005)$.

Survey of year 1 GP trainees in Aug 2013 and $2014,76 \%$ of those surveyed had viewed the blog

- $48 \%$ of those surveyed the blog had influenced the choice of location for training - The fill rate at the end of round 1 was up to $71 \%$ in 2013 and $81 \%$ in 2014 from an average of $60 \%$ in the years prior to the blog. (At this time the overall recruitment in Scotland remained static.)

- One municipality had recruited and lost 73 GPs in 10 years prior to this scheme - 2 years from the start of the programme in Feb 20074 of 10 GP applicants signed a job contract, 2 with GP specialist qualifications and 2 residents.

Double salary for $1^{\text {st }}$ and last month plus travel allowance

$58 \%$ of rural practitioners are retained for the maximum period (6 years)

- High degree of satisfaction with the program $>90 \%$ considered it a positive experience

- Applications exceed the number of available positions by at least 2.5 times 
Table 1 Description of intervention, costing and outcomes (Continued)

Management, environment and social

support incentives to engage in

hospital and community work,

continuous professional development

increased holiday and leave allocation.

External incentives - internship during

medical school

30 Alberta Rural Physician Action Plan : an integrated approach to education recruitment, and retention

Wilson (1998) [55],

Rural Incentive Programs a failing

report card

Czapski (1998) [56]

Canada

31 Ontarios Underserviced Area

Program Revisited: an indirect analysis Anderson et al. (1990) [57]

Canad

Support for professional development and research

32 Developing primary care through education

Hilton et al. (1997) [58]

UK

Academic Training in London

GP Tomorrow (book)

Freeman et al. (2002) [59]

Whole-system evaluation research

Alberta Rural Physician Action Plan:
Cross sectional non comparative $n=$ unclear Cross sectional non comparative $n=$ unclear

Cross sectional non comparative $n=$ unclear (1991 onwards) Addresses recruiting and retaining rural physicians at the medical student, resident and current physician levels.

Undergraduate medical students and residents

Rural rotations

Special skills program

Student loan remission program

Mandatory four week Family

Medicine rotation (most students in

rural Alberta)

Physicians currently practicing in

rural Alberta

CME initiatives

Enrichment program

Rural locum program

Ontarios Underserviced Area Program \$40,000 incentive payment Started in 1969 (onwards) : To place physicians in areas on Ontario

deemed to be medically underserved 36 bursaries of $\$ 5000$ awarded annually to Ontario students.

Students are expected to return

service to an underserved area

following their training (if the student

fails to fulfil the service, the bursary is

refundable with interest) $\$ 40,000$

incentive payment paid Quarterly

over 4 years for physicians

Cross sectional non

comparative

$n=$ not reported

cross sectional non

comparative

$n=49$

Cross sectional non

comparative

$n=14$

The London Initiative Zone Educationa Incentives Scheme (LIZEI) Aim of the programme was to improve

recruitment, retention and refreshment of London GPs (1994-1999)

London Academic Training scheme

(LATS) (1995-2000): To encourage GPs

to remain in the London area each

with a strong link to an academic
Government provided RPAP with funding of $£ 3.11$ million per year paid quarterly over 4 years to physicians

$\$ 5000$ student bursary

- 1995 - 35 \% of 285 responding physicians indicated the RPAP had a critical or moderate on their decision to move to or stay in rural Alberta.

By 1998 the number of rural primary care doctors had dropped $34 \%$ from

1994 baseline figure

Physician population ratios have improved

- Each northern country experienced between 35 and $80 \%$ improvement in its ratio between 1956 and 1986

- The province improved its ratio from 971 people/physician in 1956 to 560/physician in 1986

LATS: Practice pay registra 80 for medical defence subscription and travel ATS: Total budget in the first year for 12 registrars $=£ 600,000$

- 2 Years on: $75 \%$ of the first cohort continue to practice in London, with academic links

LATS: In 2000 the 49 participants of the first 4 cohorts were contacted with 37 replies. -32/37 (86\%) were working in London

• 34/37 (92\%) In general practice.

-20/37 (54 \%) were current members of 
Table 1 Description of intervention, costing and outcomes (Continued)

of a scheme to support inner city recruitment and retention of GPs

Bellman (2002) [60]

UK

33 Positive Impact of Rural Academic Family Practice on Rural Medical Recruitment and Retention in

South Australia.

Wilkinson et al. (2001) [61]

Australia
Longitudinal follow up non comparative $n=17$

Longitudinal non comparative $n=426$ and training retains and supports rural and remote doctors in

Queensland.

White (2007) [62]

Australia

Retainer schemes

35 The GP Retainer Scheme: report of a national survey. Lockyer et al. (2014) UK

36 Doctors' retainer scheme in Scotland: time for change? Douglas et al. (1996) [66] UK

Cross sectional non comparative $n=318$

Cross sectional; non comparative $n=357$ department. $71 \frac{1}{2}$ day sessions/week for academic training, 2 sessions in genera practice

GP Assistants/Research Associates:

(time period not reported) recently vocationally trained GPs provide regular clinical cover to LIZ practitioners 7 clinical sessions + sessions for research and development.

Four rural academic family practices (1995-1999) Established with support of University of Adelaide.

Doctors work for fee-for service bases (no need for financial commitment).

Strong academic component- teach-

ing students, pursuing research.

Continuing medical education opportunities (2004-2006) were provided in the aim to retain medical practitioners in rural and remote communities. Workshops on topics such as emergency cardiology.
The GP retainer scheme

(1998-present) combines a service commitment and educationa

element.

It allows a limited number of sessions in clinical practice (1-4 sessions per week, 5 years max (unless in exceptional circumstances) to aid the retention of skills when taking time out

Doctors' retainer scheme in Scotland (1972-1998) allows a limited number of sessions in clinical practice to aid the retention of skills when taking time out.

Terms: Must subscribe to a professional journal, carry out a maximum of 2 sessions per week and at least 12 per year and attend a minimum of 7 education sessions per year.

academic departments.

P Assistants/Research Associates: Participants in the 9 month sch in the gimonth scheme and scheme were contacte

- 7/14 (50\%) have become principals/partners - 10/14 (71 \%) chose to remain working

in local practices

From 1995 to 1999

- Recruitment: 17 doctors were recruited, 14 were placed in the 4 academic family practices

- Retention: 4 doctors left after an average of 20 months ( 6 months -3 years and 6 months) mean duration of appointment $=15$ months (range $=4$ months to 3 years and 6 months)

- 5/17 (24\%) of the doctors were overseas trained, 4/5 expected to stay (80 \%) permanently.

Travel, accommodation + locum support subsidised

$341 / 426$ (80 \%) of respondents agreed or strongly agreed they were less likely to remain in rural practice without access to CME workshop

Retainer payment $£ 59.18$ per session

professional expenses

Retainer fee of $£ 290+$ salary The practice receive a fee of $£ 40.50$ per session
Of those who had left the scheme in the last 2 years $(2012-2013) n=105$ were

working as:

. 91/105 (86.3\%) GPS,

$.49 / 105(47.1 \%)$ in salaried GP posts. . 25/105 (24 \%) were working as GP principals/partners

- Future plans of current retainers: 93/105 (88.6\%) planned to continue as GPs.

Length of membership 1-17 years Former members who responded $n=104$ - 76/104 (73\%) had left the scheme within 4 years - 31/104 (29\%) were GP principals/partners . 5/104 (4\%) were unemployed.

-33/104 (32 \%) stated it prevented them from leaving medicine

Of current members $n=152$

- 69/152 (46\%) stated the scheme prevented them from leaving medicine 
Table 1 Description of intervention, costing and outcomes (Continued)

37 Special provisions for women doctors to train and practice

medicine after graduation: a repor

of a survey

Beaumont (1979) [63]

UK

Review of the women's doctors

retainer scheme in Sheffield region

1972-1973 Eskin (1974) [64]

UK

Re-entry scheme

38 Putting principals back into practice: an evaluation of a re-entry course for vocationally trained doctors

Baker et al. (1997) [67]

UK

Cross sectional

non comparative

$n=2433$

Cross sectional

non comparative

$n=14$

K Women's Doctors retainer schem

(1973-1976) for female doctors in

hospital medicine, GP or that work in

the local authority health service

aged under 55; who are unemployed

(or work $\leq 2$ sessions per week)

Terms: As above and membership

with a medical defence organisation

Longitudinal follow up comparative between groups $n=14$ confidence and needs based. 8

Delayed partnership

39 Career Start in County Durham

Tomorrow's GP (Book)

Harrison

[68]

UK

40 South London Vocational Training Associate scheme seven years on GP Tomorrow (book)

Delacourt et al. (2002) [69]

UK
Cross sectional -

non comparative

$N=$ unclear

Cross sectional -

non comparative

$n=50$
Re-entry course (3 day course March 1996) developed to help doctors to return to general practice. Rebuilding

tutorial sessions (rational prescribing,

developments in therapeutics, recent advances, CPR, practice management, employment prospects) and

simulated surgeries.
GP Career Start Scheme: (1996)

2 year salaried GP Start Scheme 'Give

Vocationally trained practitioners a

further level of training to aid the

difficult transition between registrar

and principal/partner + aid the

personal and professional

development of its doctors

Year 1 sessions in mentor

practices + half day release for group

education Year 250 \% general

practice locums in County Durham

$50 \%$ Professional and personal

development

An extra structured year of

professional development (1994-

2002) in general

practice and to also allow this time as

'cover' for existing practitioners at the practice. Vocational Training

Associate scheme 7 sessions working

in 2 busy inner city practices +

research and professional

development time.
Charge $£ 450$ per delegate

Full time salary at $80 \%$ of net intended GP principal/ partner income $+/-$ a bonus of $10 \%$ of

final salary to join Durham Medical List

Not reported

(n)
19:100 \% remain working as a GP in some

Remaining in County Durham: post course

-2/14 (14 \%) have returned as principals/ partners

- 7/14 (50 \%) had made 'positive steps' to return to general practice

- Vs 1 in the control group (size of the control group not stated in text) had

made plans to return to practice

- 36/2433 (1.5\%) of respondents had been a member of the retainer scheme and

5 (14\%) in full time posts

Evaluation 2.14 doctors on the scheme employed of these subsequently (hospital doctors + GPs)

Seven recruited (5 women, 2 men) in 1996 (since then 5 further cohorts have been recruited). 19 had left the scheme by 2002 , Career destinations of the above capacity

- Principal/partner 6/19 (33\%), retained 3/19 (16\%), salaried post 2/19 (11\%) Working in wider NHS

- Principal/partner 3/19 (16\%) retained 2/19 (11\%), Salaried Post 2/19 (11\%), Locum 1/19 (5\%)

Since 1994-2002 50 GPs have been on the scheme

- 7 years on 22/50 (44 \%) still work as GP principals/partner/salaried doctors in the schemes locality

- 7/50 (14 \%) remain as assistants or

locums in the schemes locality 
Table 1 Description of intervention, costing and outcomes (Continued)

\begin{tabular}{|c|c|c|c|c|c|}
\hline \multicolumn{6}{|c|}{ Specialised recruiter/case manager } \\
\hline 41 & $\begin{array}{l}\text { Recruitment of rural health } \\
\text { care providers: a regional } \\
\text { recruiter strategy } \\
\text { Felix et al. (2003) [70] } \\
\text { USA }\end{array}$ & $\begin{array}{l}\text { Cross sectional - } \\
\text { non comparative } \\
n=8\end{array}$ & $\begin{array}{l}\text { Delta- based recruiter (DR) ( } 2000- \\
2002) \text { to assist communities with } \\
\text { health care provider recruitment and } \\
\text { retention of uses a holistic approach } \\
+ \text { encourages } \\
\text { community development activities - } \\
\text { Nurtures new providers to ease their } \\
\text { transition into their new community }\end{array}$ & $\begin{array}{l}\text { Salary and 'fringe' for } 1 \text { full } \\
\text { time } \\
\text { Delta recruiter } \$ 75,000 \text { a year } \\
\text { Average cost of } \$ 18,750 \text { per } \\
\text { recruit }\end{array}$ & $\begin{array}{l}\text { In a } 2 \text { year period } \\
\text { - DR was able to recruit } 8 \text { primary care } \\
\text { providers ( } 3 \text { primary care physicians) } \\
\text { - Previously only had access to a part } \\
\text { time rural health clinic managed by a } \\
\text { nurse practitioner }\end{array}$ \\
\hline 42 & $\begin{array}{l}\text { Case management: a model } \\
\text { for the recruitment of rural } \\
\text { general practitioners } \\
\text { Maclsaac, et al. (2000) } \\
\text { [71] } \\
\text { Australia. }\end{array}$ & $\begin{array}{l}\text { Cross sectional - } \\
\text { non comparative } \\
n=17\end{array}$ & $\begin{array}{l}\text { The West Vic Model: (Feb 1997- May } \\
\text { 1998) intensive case manager to } \\
\text { identify potential doctors, } \\
\text { assess any issues, define goals, } \\
\text { support and motivate them and help } \\
\text { ease the transition (national and } \\
\text { international recruitment) }\end{array}$ & $\begin{array}{l}\$ 1000-\$ 1500 \text { cost of } \\
\text { advertising } \\
\text { in } 2 \text { newspapers per week. } \\
\text { Other costs not detailed. }\end{array}$ & $\begin{array}{l}\text { Over } 18 \text { month period } \\
\text { - } 17 \text { doctors placed into temporary } \\
\text { or permanent placements } \\
\text { - } 4 / 17(23 \%) \text { from UK/reland }\end{array}$ \\
\hline
\end{tabular}


was a before and after comparison and six compared two parallel groups.

The representativeness of the included participants was generally good, however the absence of a comparison group resulted in a high risk of bias in many studies (Table 2). Assessment of the outcome and follow-up was generally low risk of bias. Most studies were described in an adequate or detailed manner and had potential or good generalisability. $21 / 51$ of the included studies had a conflict of interest; primarily the study authors who undertook and evaluated the intervention were part of the same organisation that delivered the intervention.

\section{Interventions tested}

Interventions could be broadly categorised into 13 groups: retainer schemes, re-entry schemes, support for professional development or research, specialised recruiters or case managers, well-being or peer support initiatives, recruiting rural students, rural or primary care focused undergraduate placements, rural or underserved postgraduate training, marketing, delayed partnerships, international recruitment, financial incentives and mixed interventions. Results are presented from strongest to weakest evidence.

\section{Financial incentives}

The strongest evidence was for financial incentives, eleven studies evaluated interventions which provided financial incentives in return for an obligation of service [21-31]. Six studies had a comparison group [21, 22, 24, 28, 29, 31]. Two Japanese studies examined a strategy which obligated students to a nine year service agreement in their home region in exchange for fully funded undergraduate training (medical school) [21, 22]. After the nine years, students were 4.2 times more likely (no statistical significance reported) to work in rural areas compared to non-obligated students [21]. A comparative study of financial incentives compared with no financial incentives in West Virginia found similar retention rates after the obligation period ( $32 \% 14 / 44$ vs $38 \% 41 / 108$ ), with no statistical significance reported [28]. A study of five separate financial incentives found that retention rates were statistically significantly higher for obligated than non-obligated doctors (Hazard ratio $0.7095 \%$ CI 0.51 to 0.96 ) [31]. Three studies, only one of which had a comparison, assessed the National Health Service Corps (NHSC) scheme in the USA which used financial incentives, loan repayment or scholarship throughout their medical education [23-25]. The only one of these studies with a comparison group showed that NHSC participants had a lower retention rate compared to nonNHSC participants $(29 \%$ versus $52 \%, p$ value $<0.001)$ [24]. One study found doctors were 3.2 times less likely to leave an underserved area if they were fulfilling a service obligation in repayment for a funding during medical school or during postgraduate training [29].

The remaining studies did not have a comparison group and were therefore difficult to draw conclusions from. A postgraduate voluntary bonding scheme in New Zealand which recruited trainees to hard-to-staff communities for five years, with payments starting after the third year and no penalty for withdrawal, found that $89 \%$ of graduates had opted out of the scheme three years after entering [26].

\section{Recruiting rural students}

Evidence to support recruiting rural students was also found. Six studies, only one of which had a comparison group, evaluated recruiting rural students to medical school, with the expectation that some would return to their home town for practice [32-37]. The comparative study found that $68 \%$ were still practicing family medicine in the same rural area up to 16 years after graduating compared to $46 \%$ in the comparison group $(p=0.03)$ [32]. While the remaining five studies [33-37] found that a large proportion of individuals recruited from rural areas subsequently work in rural areas (one study reported up to $90 \%$ ) [34], the lack of a comparison group makes it difficult to determine what would have happened if recruitment from rural areas had not taken place.

\section{International recruitment}

Four studies (three without comparison groups) evaluated international recruitment schemes [38-41]. Three initiatives waived certain visa or work requirements to enable IMGs to work in USA or Australia if they agreed to work in rural or underserved areas for an obligated period of up to ten years [39-41]. The comparative study from USA found doctors recruited entering practice without J-1 Visa Waivers in rural communities had a significantly higher retention rate than their visa waiver colleagues $(p<0.001)$ [40]. These schemes recruited IMGs with varied retention rates. All studies reported success in recruiting international doctors (range 7 to 145), but the three lacking of a comparison group were difficult to draw conclusions [38-41]. Three studies found that a significant number of IMGs did not stay in rural practice $(73 \% 19 / 26)$ [41], did not complete the three year obligation period (30 \%, 22/ 72) [40] or did not work beyond the initial years contract $(19 \%, 2 / 7)[38]$.

Rural or primary care focused undergraduate placements (i.e. undergraduate placements refers to placements during medical school)

Three studies from the USA looked at rural undergraduate placements in primary care settings [42-44]. One comparative study found that $23 \%(156 / 677)$ [44] of individuals with rural experience during their undergraduate 
Table 2 Risk of bias table: modified Newcastle Ottowa

\begin{tabular}{|c|c|c|c|c|c|c|c|c|c|c|}
\hline & Author and year & $\begin{array}{l}\text { Representativeness } \\
\text { of intervention group } \\
\text { (selection bias) }\end{array}$ & $\begin{array}{l}\text { Control } \\
\text { group }\end{array}$ & $\begin{array}{l}\text { Representativeness } \\
\text { of control group } \\
\text { (selection bias) }\end{array}$ & $\begin{array}{l}\text { Comparability of } \\
\text { intervention and } \\
\text { control group }\end{array}$ & $\begin{array}{l}\text { Adequate } \\
\text { assessment } \\
\text { of outcome }\end{array}$ & $\begin{array}{l}\text { Adequate } \\
\text { follow-up }\end{array}$ & Reporting & Generalizability & $\begin{array}{l}\text { Conflicts } \\
\text { of interest }\end{array}$ \\
\hline 1 & Lockyer L et al., (2014) [65] & Unclear & High & N/A & N/A & Low & N/A & Detailed & Good & No \\
\hline 2 & Douglas A \& McCann I, (1996) [66] & High & High & N/A & N/A & Low & $\mathrm{N} / \mathrm{A}$ & Adequate & Good & No \\
\hline 3 & Beaumont B (1979) [63] & Unclear & High & N/A & N/A & Low & N/A & Incomplete & Potential & No \\
\hline 4 & Eskin F, (1974) [64] & Low & High & N/A & $\mathrm{N} / \mathrm{A}$ & Low & Low & Detailed & Limited & No \\
\hline 5 & Baker M et al. (1997) [67] & Low & Low & Unclear & Low & Low & Low & Limited & Limited & No \\
\hline 6 & Hilton S et al. (1997) [58] & N/A & N/A & N/A & N/A & High & N/A & Detailed & N/A & Yes \\
\hline 7 & Freeman et al. (2002) & Low & High & N/A & N/A & Low & Low & Adequate & Limited & No \\
\hline 8 & Bellman L (2002) [60] & High & High & N/A & N/A & Low & N/A & Detailed & Limited & Yes \\
\hline 9 & Wilkinson D (2001) [61] & Low & N/A & N/A & N/A & Low & Low & Adequate & Potential & Yes \\
\hline 10 & White CD et al. (2007) [62] & Unclear & High & N/A & N/A & Low- & N/A & Incomplete & Limited & Yes \\
\hline 11 & Gardiner M et al. (2006) [48] & Unclear & High & N/A & $\mathrm{N} / \mathrm{A}$ & High- & Unclear & Detailed & Potential & No \\
\hline 12 & Straume et al. (2010) [50] & Low & High & N/A & N/A & Low & Low & Detailed & Potential & No \\
\hline 13 & Straume and Shaw (2010) [49] & Low & Low & Unclear & Unclear & Low & Unclear & Detailed & Potential & No \\
\hline 14 & Felix H et al. (2003) [70] & Unclear & High & N/A & $\mathrm{N} / \mathrm{A}$ & Low & N/A & Adequate & Potential & No \\
\hline 15 & Maclsaac et al. (2000) [71] & Unclear & High & N/A & N/A & Low & N/A & Adequate & Potential & Yes- \\
\hline 16 & Bregazzi R and Harrison (2005) [38] & Low & High & N/A & N/A & Unclear & Unclear & Poor & Limited & No \\
\hline 17 & Kahn TR et al. (2010) [39] & Low & High & N/A & N/A & Low & Low & Detailed & Limited & No \\
\hline 18 & Crouse BJ and Munson RL (2006) [40] & Low & High & N/A & $\mathrm{N} / \mathrm{A}$ & Low & Unclear & Adequate & Potential & No \\
\hline 19 & Robinson M and Slaney GM (2013) [41] & High & High & N/A & N/A & $\begin{array}{l}\text { Low } 2 X \\
\text { Data sets }\end{array}$ & High & Adequate & Potential & Yes \\
\hline 20 & Rabinowitz et al. (2005) [32] & Low & Low & Unclear & Unclear & Low & Low & Adequate & Potential & Yes \\
\hline 21 & Mathews M et al. (2008) [33] & Low & High & N/A & N/A & Low & Low- & Detailed & Potential & Yes \\
\hline 22 & Quinn KJ et al. (2011) [34] & Low & Low & Unclear & Unclear & Low & High & Adequate & Potential & Yes \\
\hline 23 & Landry et al. (2011) [35] & Low & Low & Unclear & Low & Low & High & Detailed & Limited & Yes \\
\hline 24 & Magnus JH \& Tollan A (1993) [36] & Low & High & N/A & $\mathrm{N} / \mathrm{A}$ & High & Low & Adequate & Potential & Yes \\
\hline 25 & Stearns et al. (2000) [37] & Low & High & N/A & N/A & Low & Unclear & Limited & Potential & Yes \\
\hline 26 & Halaas et al. (2008) [42] & Low & High & N/A & N/A & Low- & Unclear-' & Detailed & Good & Yes \\
\hline 27 & Smucny J et al. (2005) [43] & High & Low & Low & Unclear & Low & High & Adequate & Good & Yes \\
\hline 28 & Adkins et al. (1987) [44] & Low & Low & Unclear & Unclear & Low & Low & Adequate & Potential & Yes \\
\hline 29 & Wearne S et al. (2010) [46] & Low & High & N/A & N/A & Low & Low & Detailed & Limited & Yes \\
\hline 30 & Charles et al. (2005) [45] & Low & High & N/A & N/A & Low & Low & Adequate & Potential & No \\
\hline 31 & Morris CG et al. (2008) [47] & Low & Low & Low & Low & Low & Unclear & Detailed & Potential & No \\
\hline
\end{tabular}


Table 2 Risk of bias table: modified Newcastle Ottowa (Continued)

\begin{tabular}{|c|c|c|c|c|c|c|c|c|c|c|}
\hline 32 & Barclay et al. (1994) [51] & Low & Low & Unclear & Unclear & High- & Unclear & Poor & Limited & Yes \\
\hline 33 & Paul Green (2015) [52] & Unclear & N/A & $\mathrm{N} / \mathrm{A}$ & N/A & High & Low & Limited & Potential & Unclear \\
\hline 34 & Harrison J and Redpath L (2002) [68] & High & High & N/A & N/A & Unclear & Low & Adequate & Potential & No \\
\hline 35 & Delacourt L and Savage R (2002) [69] & Low & High & N/A & N/A & Unclear & Low & Adequate & Potential & No \\
\hline 36 & Matsumoto M et al. (2008) [21] & Low & Low & Low & Unclear & Low & Low & Detailed & Good & No \\
\hline 37 & Matsumoto M et al. (2008) [22] & Low & High & N/A & N/A & Low & Low & Detailed & Good & No \\
\hline 38 & $\begin{array}{l}\text { US department of Health and Human services } \\
\text { Health resources and services } \\
\text { administration(2012) [23] }\end{array}$ & Unclear & High & N/A & N/A & High & Low & Limited & Potential & Yes \\
\hline 39 & Pathman D et al. (1992) [24] & Low & Low & Unclear & High & Low & Low & Detailed & Good & Yes \\
\hline 40 & Cullen TJ et al. (1997) [25] & Low & High & N/A & N/A & Low- & Low & Detailed & Good & No \\
\hline 41 & New Zealand Ministry of Health (2012) [26] & Unclear & High & N/A & N/A & High & Unclear & Limited & Potential & No \\
\hline 42 & Dunbabin JS et al. (2006) [27] & High - & High & N/A & N/A & Low & Low & Adequate & Potential & Yes \\
\hline 43 & Jackson J et al. (2003) [28] & Low & Low & Low & High & Low & Low & Adequate & Limited & NO \\
\hline 44 & Mathews M et al. (2013) [29] & Low & Low & Low & Low & Low & Low & Adequate & Good & Yes \\
\hline 45 & Navin TR and Nichols AW (1977) [30] & Low & High & N/A & N/A & Low & Low & Detailed & Limited & Yes \\
\hline 46 & Pathman et al. (2004) [31] & High & Low & Low & Low & Low & Low & Adequate & Good & No \\
\hline 47 & WONCA (2010) [53] & Unclear & High & N/A & N/A & Unclear & Unclear & Limited & Limited & No \\
\hline 48 & Pena S et al. (2010) [54] & Unclear & High & N/A & N/A & Unclear & Unclear & Limited & Limited & No \\
\hline 49 & Wilson et al. (1998) [55] & Unclear & High & N/A & N/A & High & Unclear & Limited & Limited & No \\
\hline 50 & Hutten - Czapski (1998) [56] & N/A & N/A & N/A & N/A & High & Unclear & Limited & Limited & No \\
\hline 51 & Anderson M \& Rosenberg (1990) [57] & N/A & N/A & N/A & N/A & High & Low & Detailed & Limited & No \\
\hline
\end{tabular}


were practicing in rural areas compared to $12 \%(32 / 260)$ [44] of students without (statistical significance not reported). One study found a higher percentage of graduates with rural exposure in medical school subsequently worked in rural areas than those without $(n=1393,26 \%$ vs $7 \%, p<0.001$ ) [43]. The final study reported a high proportion of students practicing primary care in rural areas after rural placements, but without a comparison group it is difficult to draw conclusions [43].

\section{Rural or underserved postgraduate training}

Three studies evaluated postgraduate training in rural/ underserved areas [45-47]. One comparative study from the USA found that doctors who were trained in a community health centre serving underserved communities were statistically significantly more likely (odds ratio 2.7 , $95 \%$ CI 1.6 to 4.7 ) to work in underserved areas compared to doctors who had not [47]. Two studies from Australia did not have a comparison group but one reported that a small percentage (14 \%) of individuals reported that they were influenced against rural practice after their placements [45].

\section{Well- being or peer support initiatives}

Three studies provided social and emotional support to rurally isolated doctors [48-50]. One Australian study using a before and after comparison found a moderate reduction of $5 \%$ (98/187 compared with 102/221, statistical significance not reported) in those planning to leave rural practice after a support initiative was introduced [48]. Two studies from northern Norway reported on a tutorial group which primarily provided support for postgraduate

doctors serving an internship in a rural area $[49,50]$. The authors found good recruitment (twice as many as expected) [49] and retention (65\% five year retention) [50], but the results were confounded by place of graduation and growing up in that area making it impossible to disaggregate the effects of the tutorial group.

\section{Marketing}

Two studies evaluated marketing strategies for recruiting residents to a primary care training program [51, 52]. A promotional video marketing in the USA was associated with lower recruitment with only $29 \%(35 / 120)$ of those receiving the video applied compared to $54 \%(69 / 128)$ of those who did not $(p<0.0001)$ [51]. In a noncomparative study, $48 \%$ of trainees recruited in the North of Scotland study stated that a blog which posted views and experiences of current primary care trainees positively influenced their choice of location for primary care training [52].

\section{Mixed incentives}

Weak evidence was found for mixed incentives. Five small studies [53-57] evaluated mixed incentives, combining continued medical education, financial and undergraduate placement incentives to recruit and retain doctors, with mixed results. None of the studies included a comparison group and therefore it is difficult to draw conclusions about either individual components or the intervention as a whole.

Two of these studies evaluated one scheme in Alberta, which used financial incentives, CME and rotations aimed at undergraduates, postgraduates and currently practicing doctors $[56,57] 35 \%$ indicated the scheme had a critical or moderate effect on their decision to move or stay in Alberta but after the scheme was initiated the number of rural primary care doctors in Alberta actually reduced [56].

\section{Support for professional development and academic opportunities}

Five studies, without a comparison group, focused on interventions which aimed to provide primary care doctors with an increase in academic skills, particularly in teaching and research [58-62]. Three studies reported the London Initiative Zone Educational Incentive scheme (LIZEI) aimed to improve recruitment, retention and refreshment of London GPs via various schemes which focused on increasing the academic aspect of training through academic/research associate schemes [58-60]. The scheme reported high levels of retention $(75 \%$ from the London Academic Training Scheme (LATS) cohort continued to practice in London) [58], but the lack of a comparison group makes this difficult to interpret, two further studies echoed this result, and found high levels of retention in London [59, 60]. The two other studies were from Australia [61, 62]. One found that $80 \%$ of attendees (341/ 426) of continuing medical education (CME) workshops reported that they were less likely to remain in rural practice without CME [62]. The other study lack sufficient detail to allow interpretation of the results [61].

\section{Retainer schemes}

Four studies, without a comparison group, assessed retainer schemes in the UK, including the Women's Doctors Retainer Scheme [63, 64], the GP retainer scheme [65] and the Doctors' retainer scheme [66]. Retainer schemes allow primary care doctors to work reduced hours (a maximum of four sessions a week, a minimum of one) with an educational component, for up to five years. Participants from a retainer scheme in Scotland reported that the scheme prevented them leaving medicine $(32 \%$ of former members $(33 / 104)$ and $46 \%$ of current members (69/152) [66]. All studies showed high retention of primary care doctors from retainer schemes 
(86 \% (91/105) [65], $91 \%(33 / 36)$ [63] and $71 \%(10 / 14)$ [64] but the lack of a comparator group made it difficult to draw conclusions about the effect of the scheme.

\section{Re-entry schemes}

One small study [67] with a comparison group evaluated a re-entry scheme, developed to help doctors to return to general practice as a partner (i.e. partner is a term used in the UK for a GP who makes a financial investment into a practice, and can therefore benefits from any profits (or losses) it makes, they must also oversee how the practice is run). The scheme rebuilt their confidence using needs based tutorials. Six months after the course 2 out of 14 attendees had returned to working as partners. 11 out of 14 attendees had taken 'positive steps' (this was not explained further) to return to general practice or had increased their time commitment to medicine. Compared with 1 in the control group (comparison group denominator not reported), who had 'made plans' to return to general practice [67]. The numbers were too small to draw conclusions.

\section{Delayed partnership}

Weak evidence was found for the value of delayed partnerships. Two studies without comparison groups looked at delaying partnership after GP training by adding up to two years of post-vocational training $[68,69]$. This included sessions at a mentor practice gaining general experience, varied locum experience and protected time for further training education [68]. Another scheme added one year of extra training which included exposure to the financial, managerial aspects of partnership, as well as clinical time [69]. The lack of a comparison group made it impossible to draw conclusion about the effectiveness of delayed partnerships.

\section{Specialised recruiter or case managers}

The weakest evidence was found for specialised recruiters or case managers. Two cross sectional studies (non-comparative) used specialised recruiters or case managers to recruit doctors to rural areas [70,71]. They provided a holistic approach to recruitment, identifying any particular needs of the doctor, helping to support them through the transition and encouraging community development activities. While both studies reported successful recruitment (17 doctors in 18 months [71] and 8 primary care providers in two years [70]), the impact of a case manager is unclear without a comparison group. A bachelor's degree in a health related field plus health related work experience (two years minimum) was required for the specialised recruiter post in the USA, but was not compulsory [70].

\section{Discussion}

This is the first systematic review to assess interventions to improve recruitment and retention of primary care doctors. The studies were all of low methodological quality, and only 15 of the 51 included studies involved a comparison group. There is weak evidence from these 15 studies that improved recruitment of primary care doctors was associated with postgraduate placements in underserved areas, undergraduate rural placements and recruiting students to medical school from rural areas. There was weak mixed evidence about financial incentives. The quality of the studies was not sufficient to draw conclusions about retainer schemes, re-entry schemes, international recruitment, specialised recruiters, support for professional development or research, delayed partnerships, well-being or peer support or mixed approaches.

\section{Strengths and limitations}

Strengths of this review included that an inclusive search was undertaken with a robust process for screening and extraction of data. Grey literature was extensively searched and yielded six additional studies. Authors were contacted when necessary and this resulted in two additional studies. The methodological quality was assessed using a modified Newcastle Ottawa Scale, to elicit particular methodological problems. The response rate for the questionnaire based studies varied between 55 and $100 \%$. An online survey achieved a $100 \%(24 / 24)$ response rate [46].

The methodological quality of the included studies was low as there were no RCTs and many of the studies did not include a control group or comparator. 21/51 of the included studies had some conflict of interest.

Studies without a defined intervention were excluded, this may have restricted our search however we wanted to evaluate how well interventions worked, not simply find relationships or factors which influence recruitment and retention. In eight studies the outcome was the selfreported location of where the trainee or doctor was practicing after the intervention, which may be open to reporting bias.

Sample sizes were generally small and 7 studies had less than 20 participants, which may affect the generalisability of the results. Some studies may have been affected by selection bias as for example students with an interest in rural medicine and intentions to continue with it may be more likely to join a rural based university or program.

Many of the interventions were tested in the USA, Canada or rural Australia. Whilst this may limit generalisability to other countries and health systems, the principles and theory behind the interventions such as providing placements in underserved areas should be considered for undergraduate and postgraduate training for primary care may be transferable. There was great 
variability in reported outcome measures and 'retention rates'. Some studies regarded the intention to stay in the area after an intervention as retention, whilst others considered the length of duration post- intervention as retention. The heterogeneity of outcome measure made comparison between studies difficult and meta-analysis impossible.

\section{Comparison with previous research}

Previous systematic reviews of strategies to increase attraction and retention of health workers in rural areas found some evidence to support the use of financial incentives, and insufficient evidence for increasing professional support, support for medical education and educational initiatives [72, 73]. A systematic review of recruitment and retention of primary care doctors in rural Canada and Australia found that factors before medical school were associated with future practice location, and that those who had been bought up or completed high school in rural areas were subsequently more likely to work there [72]. Rural experiences in postgraduate training, financial incentives, and support for professional development were found to be valuable [72].

\section{Comparison of our findings with existing recommendations}

In the UK the 10 Point Plan [15] plans to introduce an additional flexible year, after completion of training to recruit trainees to underserved areas is planned [15]. This was supported by our research which found that doctors who completed their training in underserved areas were statistically significantly more likely to practice there. The report also sets out a plan to explore a three year financial incentive scheme to offer additional financial support to GP trainees committed to working in underserved areas [15]. Our research found mixed results for the use of financial incentives. They were found to be particularly successful when tying in trainees who had existing links to the underserved area [21], and when there is a long period of service obligation and more flexibility in career opportunities [21, 22, 62]. Financial incentives may need to be tied into public sector service with clear guards against direct personal profit.

A new induction and refresher scheme has been recently introduced in the UK by Health Education England and aims to support GPs to return to the workforce in England [16]. The GP taskforce final report recommends funding of a returners scheme - prioritising funding in under-doctored areas [4]. Our research did not find sufficient evidence to support or refute this. A marketing campaign is set to be implemented (a recruitment video outlining the positive aspects of general practice has already been distributed by RCGP). Our research found that video marketing may have a negative effect on recruitment.

\section{Implications for research and policy and conclusions}

Despite the large number of reports and studies on the primary care doctors workforce crisis, and papers describing factors which influence recruitment and retention there is little evidence about which interventions are actually effective. As is pointed out in the recommendations of the Roland Commission [74], policy makers and health planners cannot learn from previous initiatives without published high quality evaluation, and unsuccessful strategies risk being reintroduced repeatedly, and consequently substantive amounts of funding wasted.

The evidence from this review also suggests that selection and educational exposures are important and that students are likely to be retained in a rural or underserved area if they have connections to the area, and are exposed to good educational primary care placements. Despite the recruitment crisis, clinical time as an undergraduate remains dominated by hospitals in many UK medical schools, and there is a great disparity between the numbers of graduates who eventually training as GPs. The 2015 F2 Career Destination Report shows that some UK universities are producing significantly more graduates who go on and apply to GP training than others, with Oxford and Cambridge behind others (see Table 3) [75]. Medical schools have a responsibility to start taking notice of the workforce crisis in primary care and perhaps resources and funding for these Universities should be based on output to meet targets. Furthermore if the UK is to meet the targets of $50 \%$ of medical students entering primary care, we must consider more medical school training to be in GP and resources to support this must be provided. Universities should be held accountable as to how much time they allocate to the primary care setting and this data should be made publically available. The current work plan for primary care doctors is outdated, there is a need for change to reflect the change in the workforce. As the recruitment crisis worsens we believe these methods should be trialled on a larger scale.

More research is needed to identify evidence-based solutions to the primary care doctor workforce crisis and specific interventions to encourage more doctors into deprived areas that are currently under-served. Evaluations should be designed into all new recruitment initiatives and should include a comparison group (e.g. before and after, multicentre comparative, or formal trial) and these should then be made publically available. Retention based initiatives/interventions must also be tested to help streamline the current process of qualified GPs returning to work after a career break, and to help aid the loss of doctors to overseas positions, or those choosing to leave the profession entirely. Novel theory-based 
Table 3 The table below shows the percentage of respondents who were appointed to GP specialty training in the UK from each UK foundation school

\begin{tabular}{|c|c|c|}
\hline Rank & UK Medical School & $\begin{array}{l}\% \text { appointed to } \\
\text { GP training in UK }\end{array}$ \\
\hline 1 & Lancaster School of Health and Medicine & $30.0 \%$ \\
\hline 2 & Keele University & $29.5 \%$ \\
\hline 3 & University of Aberdeen & $26.9 \%$ \\
\hline 4 & University of East Anglia & $26.6 \%$ \\
\hline 5 & University of Leicester & $26.4 \%$ \\
\hline 6 & Hull York Medical School & $26.3 \%$ \\
\hline 7 & Queen Mary University of London & $25.7 \%$ \\
\hline 8 & University of Warwick & $24.7 \%$ \\
\hline 9 & St Georges, University of London & $22.2 \%$ \\
\hline 10 & The University of Sheffield & $21.6 \%$ \\
\hline 11 & Cardiff University & $20.5 \%$ \\
\hline 12 & University of Leeds & $19.2 \%$ \\
\hline 13 & Kings College & $19.1 \%$ \\
\hline 14 & University of Liverpool & $18.9 \%$ \\
\hline 15 & University of Dundee, Faculty of Medicine & $18.2 \%$ \\
\hline 16 & Peninsula College of Medicine and Dentistry & $17.5 \%$ \\
\hline 17 & University of Glasgow & $17.5 \%$ \\
\hline 18 & University of Birmingham & $16.8 \%$ \\
\hline 19 & University of Nottingham & $15.7 \%$ \\
\hline 20 & Brighton and Sussex Medical School & $15.6 \%$ \\
\hline 21 & Imperial College School of Medicine & $15.4 \%$ \\
\hline 22 & University of Manchester & $13.0 \%$ \\
\hline 23 & University of Newcastle & $12.6 \%$ \\
\hline 24 & University of Bristol & $11.3 \%$ \\
\hline 25 & University College London & $10.8 \%$ \\
\hline 26 & Queens University Belfast & $10.6 \%$ \\
\hline 27 & The University of Southampton & $10.5 \%$ \\
\hline 28 & The University of Edinburgh & $10.4 \%$ \\
\hline 29 & University of Oxford & $9.2 \%$ \\
\hline 30 & University of Cambridge & $7.3 \%$ \\
\hline
\end{tabular}

strategies such as case managers, improved support for professional development, and well-being and peer support should be evaluated.

\section{Conclusions}

Although the evidence base for recruiting and retaining primary care doctors is weak and more high quality research is needed, this review found evidence to support undergraduate and postgraduate placements in underserved areas, and selective recruitment of medical students. The other initiatives covered in this review all have potential to improve recruitment and retention of primary care practitioners, but their effectiveness is not yet established.

\section{Ethical approval}

None required. No primary data collection.

\section{Consent for publication \\ Not applicable.}

\section{Availability of data}

No additional data available.

\section{Appendix 1 \\ MEDLINE search strategy}

1. exp physician/

2. exp general practice/

3. general practitioner*.tw.

4. (family adj doctor*).tw.

5. GP*.tw.

6. general practitioner/

7. physicians, family/

8. physicians, primary care/

9. doctor*.tw.

10. 1 or 2 or 3 or 4 or 5 or 6 or 7 or 8 or 9

11. exp personnel selection/

12. (recruit* adj2 (GP* or doctor* or (medical adj (personnel or staff or professional* or worker*)) or (General adj practitioner*) or (family adj physician*) or (family adj doctor*))).tw.

13. (retain* adj2 (GP* or doctor* or (medical adj (personnel or staff or professional* or worker*)) or (General adj practitioner*) or (family adj physician*) or (family adj doctor*))).tw.

14. (retention* adj2 (GP* or doctor* or (medical adj (personnel or staff or professional* or worker*)) or (General adj practitioner*) or (family adj physician*) or (family adj doctor*))).tw.

15. 11 or 12 or 13 or 14

16. 10 and 15

17. limit 16 to humans

\section{Search strategy EMBASE 3/12/14}

1. exp physician/

2. exp general practice/

3. general practitioner*.tw.

4. (family adj doctor\%).tw.

5. GP*.tw.

6. general practitioner/

7. physicians, family/

8. physicians, primary care/

9. doctor*.tw.

10. 1 or 2 or 3 or 4 or 5 or 6 or 7 or 8 or 9

11. (recruit* adj2 (GP* or doctor* or (medical adj (personnel or staff or professional* or worker*)) or 
(General adj practitioner*) or (family adj physician*) or (family adj doctor*))).tw.

12. (retain* adj2 (GP* or doctor* or (medical adj (personnel or staff or professional* or worker*)) or (General adj practitioner*) or (family adj physician*) or (family adj doctor*))).tw.

13. (retention* adj2 (GP* or doctor* or (medical adj (personnel or staff or professional* or worker*)) or (General adj practitioner*) or (family adj physician*) or (family adj doctor*))).tw.

14. "personnel management/

15. 11 or 12 or 13 or 14

16. 10 and 15

17. limit 16 to human

\section{Abbreviations}

AS: Arabella Stuart; CME: continuing medical education; GP: general practitioner; IMG: international medical graduates; JF: John Ford;

LATS: London Academic Training Scheme; LIZEI: London Initiative Zone Educational Incentive Scheme; NHS: National Health Service; NHSC: National Health Service Corps; NS: Nick Steel; PV: Puja Verma; RCGP: Royal College of General Practitioners; RCT: randomised controlled trial; UK: United Kingdom; USA: United States of America; WHO: World Health Organisation.

\section{Competing interests}

All authors have completed the ICMJE uniform disclosure form and declare: no support from any organisation for the submitted work; no financial relationships with any organisations that might have an interest in the submitted work in the previous three years, AH is an Officer of the RCPGP and has national involvement with Health Education England, SE is a Trustee of the Kings Fund, Chair of Tower Hamlets CCG, Advisor to NHS England and member of the BMA Council but none of these relationships of AH or SE have influenced the submitted work.

\section{Authors' contributions}

JF conceived the idea. All authors contributed to the design of the study. PV, JF and AS screened titles and abstracts and extracted data with help from NS. JF and NS supervised day-to-day activities. NS and AH provided detailed editorial comment and policy guidance, and SE provided clinical expertise throughout. PV and AS carried out risk of bias for all studies. All authors contributed to interpretation of the results. PV drafted the initial manuscript and all authors were involved in revising and agreeing the final manuscript. $\mathrm{JF}$ is the guarantor and affirms that the manuscript is an honest, accurate, and transparent account of the study being reported; that no important aspects of the study have been omitted; and that any discrepancies from the study as planned (and, if relevant, registered) have been explained. All authors read and approved the final manuscript.

\section{Acknowledgments}

We thank John Howard and Krishna Kasaraneni for their helpful comments.

\section{Protocol}

Not published.

\section{Funding}

This research received no specific grant from any funding agency in the public, commercial or not-for-profit sectors.

\footnotetext{
Author details

${ }^{1}$ Faculty of Medicine and Health Sciences, Norwich Medical School, University of East Anglia, Chancellors Drive, Norwich NR4 7TJ, UK. ${ }^{2} \mathrm{NHS}$ Tower Hamlets CCG, Alderney Building, Mile End Hospital, London E1 4DG, UK.
}

Received: 29 June 2015 Accepted: 1 April 2016 Published online: 12 April 2016

\section{References}

1. World Health Organization (WHO). The World Health Report 2006: Working together for health; Geneva; 2006.p.1-209 http://www.who.int/whr/2006. Accessed 5 Jun 2015.

2. Global Health Workforce Alliance. Global Health Workforce Crisis: Key Messages Geneva, Switzerland; 2013.p.15. http://www.who.int/ workforcealliance/media/KeyMessages_3GF.pdf. Accessed 5 Jun 2015.

3. World Health Report: Primary Health Care (Now More Than Ever). World Health Organization Geneva, Switzerland; 2008.p.1-122. http://www.who.int/ whr/2008/en/. Accessed 5 Jun 2015.

4. GP Taskforce. Securing the future GP workforce. Delivering the mandate on GP expansion. GP taskforce final report; 2014.p.1-63 https://www. hee.nhs.uk/sites/default/files/documents/GP-Taskforce-report.pdf. Accessed 5 Jun 2015.

5. Royal College of General Practitioners (RCGP). Over 500 surgeries at risk of closure as GP workforce crisis deepens RCGP; 2014. http://www.rcgp.org.uk/ news/2014/october/over-500-surgeries-at-risk-of-closure-as-gp-workforcecrisis-deepens.aspx. Accessed 5 Jun 2015.

6. Department of Health (DOH). Delivering high quality, effective, compassionate care: Developing the right people with the right skills and the right values; 2013.p.1-40 https://www.gov.uk/government/uploads/ system/uploads/attachment_data/file/203332/29257_2900971_Delivering_ Accessible.pdf. Accessed 5 Jun 2015.

7. Petchey R, Williams J, Baker M. 'Ending up a GP': a qualitative study of junior doctors' perceptions of general practice as a career. Fam Pract. 1997;14:194-8.

8. Abbt N, Alderson S. Why doesn't anyone want to be a GP: and what can we do about it? Br J Gen Pract. 2014;64:579-79.

9. Health Education East of England. Primary care workforce development; HEEoE: update to board 28th January 2015.

10. British Medical Association (BMA). BMA quarterly tracker survey. 2014. http:// bma.org.uk/working-for-change/policy-and-lobbying/training-andworkforce/omnibus-survey-gps. Accessed 5 Jun 2015.

11. Hann M, McDonald J, Checkland K, Coleman A, Gravelle H, Sibbald B, et al. Seventh national GP worklife survey. Aug 2013. http://www.populationhealth.manchester.ac.uk/healtheconomics/research/reports/ FinalReportofthe7thNationalGPWorklifeSurvey.pdf. Accessed 5 Jun 2015.

12. Department of Health (DOH). Report of the Chair of theNational Working Group on Women in Medicine. Women doctors: making a difference; 2009. p.1-73 www.dh.gov.uk/en/Publicationsandstatistics/Publications/ PublicationsPolicyAndGuidance/DH_106894. Accessed 5 Jun 2015.

13. Sidhu K. Overseas doctors and the GP recruitment crisis. BMJ Careers. 2014. http://careers.bmj.com/careers/advice/view-article.html?id=20020042. Accessed 5 Jun 2015.

14. The King's Fund. Improving the Quality of Care in General Practice. Independent inquiry into the quality of care in general practice in England; 2011.p.1-169 www.kingsfund.org.uk/publications/gp_inquiry_report.html. Accessed 5 Jun 2015.

15. NHS England, HEE, RCGP, BMA, Building the Workforce - the New Deal for General Practice 2015. http://www.england.nhs.uk/commissioning/wpcontent/uploads/sites/12/2015/01/building-the-workforce-new-deal-gp.pdf. Accessed 5 Jun 2015.

16. James M, Harris MJ. Brazil's family health strategy — delivering communitybased primary care in a universal health system. N Engl J Med. 2015;372: 2177-81. doi:10.1056/NEJMp1501140.

17. Thorlby R, Smith J, Barnett, Mays N. Primary Care for the 21st Century: Learning from New Zealand's Independent Practitioner Associations. Nuffield Trust, 2012. http:/wwww.nuffieldtrust.org.uk/sites/files/nuffield/publication/new_zealand_ipas_ 260912-update.pdf. Accessed 22 Jun 2015.

18. Royal College of General Practitioners (RCGP). Future GP: Recruitment Video. 2015 https://www.youtube.com/watch?v=U2YaTKDAMXs\&feature=youtu.be. Accessed 5 Jun 2015.

19. NHS England, HEE, RCGP, BMA. Building the workforce-the new deal for general practice. The GP Induction \& Refresher Scheme 2015-2018; 2015. https://gprecruitment.hee.nhs.uk/Induction-Refresher. Accessed 5 Jun 2015.

20. Ottowa Hospital Research Institute. The Newcastle-Ottawa Scale (NOS) for assessing the quality of nonrandomised studies in meta-analyses; 2014. http://www.ohri.ca/programs/clinical_epidemiology/oxford.asp. Accessed 5 Jun 2015.

21. Matsumoto M, Inoue K, Kajii E. A contract-based training system for rural physicians: follow-up of Jichi Medical University graduates (1978-2006). J Rural Health. 2008;24:360-8. 
22. Matsumoto M, Inoue K, Kajii E. Long-term effect of the home prefecture recruiting scheme of Jichi Medical University, Japan. Rural Remote Health. 2008;8:930.

23. NHSC Corps [online]. NHSC Clinician Retention: A story of dedication and commitment. Secondary NHSC Clinician Retention: A story of dedication and commitment; 2012. : https://nhsc.hrsa.gov/currentmembers/ membersites/retainproviders/retentionbrief.pdf. Accessed 5 Jun 2015.

24. Pathman DE, Konrad TR, Ricketts 3rd TC. The comparative retention of National Health Service Corps and other rural physicians. Results of a 9-year follow-up study. JAMA. 1992;268:1552-8.

25. Cullen TJ, Hart LG, Whitcomb ME, Rosenblatt RA. The National Health Service Corps: rural physician service and retention. J Am Board Fam Pract. 1997:10:272-9.

26. New Zealand Ministry of Health. Voluntary Bonding Scheme; 2012. http:// www.health.govt.nz/our-work/health-workforce/voluntary-bonding-scheme Accessed 5 Jun 2015.

27. Dunbabin JS, McEwin K, Cameron I. Postgraduate medical placements in rural areas: their impact on the rural medical workforce. Rural Remote Health. 2006;6:481.

28. Jackson J, Shannon CK, Pathman DE, Mason E, Nemitz JW. A comparative assessment of West Virginia's financial incentive programs for rural physicians. J Rural Health. 2003;19(Suppl):329-39.

29. Mathews M, Heath SL, Neufeld SM, Samarasena A. Evaluation of physician return-for-service agreements in Newfoundland and Labrador. Healthcare Policy Politiques de sante. 2013:8:42-56.

30. Nichols N. Evaluation of the Arizona Medical Student Exchange Programe. J Med Educ. 1977:52:817-23.

31. Pathman DE, Konrad TR, King TS, Taylor DH, Koch GG. Outcomes of states' scholarship, loan repayment, and related programs for physicians. Med Care 2004:42:560-8

32. Rabinowitz HK, Diamond JJ, Markham FW, Rabinowitz C. Long-term retention of graduates from a program to increase the supply of rural family physicians. Acad Med. 2005;80:728-32.

33. Mathews M, Rourke JT, Park A. The contribution of Memorial University's medical school to rural physician supply. Can J Rural Med. 2008;13:15-21.

34. Quinn KJ, Kane KY, Stevermer JJ, Webb WD, Porter JL, Williamson HA, et al Influencing residency choice and practice location through a longitudinal rural pipeline program. Acad Med. 2011;86:1397-406.

35. Landry M, Schofield A, Bordage R, Belanger M. Improving the recruitment and retention of doctors by training medical students locally. Med Educ. 2011:45:1121-9.

36. Magnus $\mathrm{JH}$, Tollan A. Rural doctor recruitment: does medical education in rural districts recruit doctors to rural areas? Med Educ. 1993;27:250-3.

37. Stearns JA, Stearns MA, Glasser M, Londo RA. Illinois RMED: a comprehensive program to improve the supply of rural family physicians. Fam Med. 2000;32:17-21.

38. Bregazzi R, Harrison J. From Spain to County Durham; experience of crosscultural general practice recruitment. Educ Prim Care. 2005;16:268-74.

39. Kahn TR, Hagopian A, Johnson K. Retention of J-1 visa waiver program physicians in Washington State's health professional shortage areas. Acad Med. 2010;85:614-21.

40. Crouse BJ, Munson RL. The effect of the physician J-1 visa waiver on rural Wisconsin. WMJ. 2006;105:16-20.

41. Robinson M, Slaney GM. Choice or chance! The influence of decentralised training on GP retention in the Bogong region of Victoria and New South Wales. Rural Remote Health. 2013;13:2231.

42. Halaas GW, Zink T, Finstad D, Bolin K, Center B. Recruitment and retention of rural physicians: outcomes from the rural physician associate program of Minnesota. J Rural Health. 2008;24:345-52.

43. Smucny J, Beatty P, Grant W, Dennison T, Wolff LT. An evaluation of the Rural Medical Education Program of the State University Of New York Upstate Medical University, 1990-2003. Acad Med. 2005;80:733-8.

44. Adkins RJ, Anderson GR, Cullen TJ, Myers WW, Newman FS, Schwarz MR. Geographic and specialty distributions of WAMI Program participants and nonparticipants. J Med Educ. 1987;62:810-7.

45. Charles DM, Ward AM, Lopez DG. Experiences of female general practice registrars: are rural attachments encouraging them to stay? Aust J Rural Health. 2005;13:331-6.

46. Wearne S, Giddings P, McLaren J, Gargan C. Where are they now? The career paths of the remote vocational training scheme registrars. Aust Fam Physician. 2010;39:53-6.
47. Morris CG, Johnson B, Kim S, Chen F. Training family physicians in community health centers: a health workforce solution. Fam Med. 2008;40:271-6.

48. Gardiner M, Sexton R, Kearns H, Marshall K. Impact of support initiatives on retaining rural general practitioners. Aust J Rural Health. 2006;14:196-201.

49. Straume K, Shaw DM. Internship at the ends of the earth - a way to recruit physicians? Rural Remote Health. 2010;10:1366.

50. Straume K, Sondena MS, Prydz P. Postgraduate training at the ends of the earth - a way to retain physicians? Rural Remote Health. 2010;10:1356.

51. Barclay 3rd DM, Lugo V, Mednick J. The effects of video advertising on physician recruitment to a family practice residency program. Fam Med. 1994;26:497-9.

52. Green $P$. The effect of a blog on recruitment to general practitioner specialty training in the north of Scotland. Educ Prim Care. 2015;26:113-5.

53. Steinert S. Proceedings of the WONCA Conference; 2010 Recruiting and Retaining GPs to remote areas in Northern Norway: The Senja Doctor Project: University of Tromso. Cancun, Mexico http://www.nsdm.no/filarkiv/ File/presentasjoner/WONCA_2010_Svein_Steinert.pdf. Accessed 5 Jun 2015.

54. Pena S, Ramirez J, Becerra C, Carabantes J, Arteaga O. The Chilean Rural Practitioner Programme: a multidimensional strategy to attract and retain doctors in rural areas. Bull World Health Organ. 2010;88:371-8.

55. Wilson DR, Woodhead-Lyons SC, Moores DG. Alberta's Rural Physician Action Plan: an integrated approach to education, recruitment and retention. CMAJ. 1998:158:351-5.

56. Czapski P. Rural incentive programs: a failing report card. Can J Rural Med. 1998;3:242-7.

57. Anderson M, Rosenberg MW. Ontario's underserviced area program revisited: an indirect analysis. Soc Sci Med. 1990;30:35-44.

58. Hilton $\mathrm{S}$, Hill A, Jones R. Developing primary care through education. Fam Pract. 1997;14:191-3.

59. Freeman G, Fuller J, Hilton S, Smith F et al. Academic Training in London. In: GP Tomorrow, Harrison J and Van Zwanberg T editors. Abingdon, Oxford: Radcliffe Medical Press; 2002. p. 117-125.

60. Bellman L. Whole-system evaluation research of a scheme to support inner city recruitment and retention of GPs. Fam Pract. 2002;19:685-90.

61. Wilkinson D, Symon B, Newbury J, Marley JE. Positive impact of rural academic family practices on rural medical recruitment and retention in South Australia. Aust J Rural Health. 2001;9:29-33.

62. White CD, Willett K, Mitchell C, Constantine S. Making a difference: education and training retains and supports rural and remote doctors in Queensland. Rural Remote Health. 2007;7:700.

63. Beaumont B. Special provisions for women doctors to train and practise in medicine after graduation: a report of a survey. Med Educ. 1979;13:284-91.

64. Eskin F. Review of the women doctors' retainer scheme in the Sheffield region 1972-73. Br J Med Educ. 1974;8:141-4.

65. Lockyer L, Young P, Main PG, Morison J. The GP retainer scheme: report of a national survey. Educ Prim Care. 2014;25:338-46.

66. Douglas A, McCann I. Doctors' retainer scheme in Scotland: time for change? BMJ. 1996;313:792-4.

67. Baker M, Williams J, Petchey R. Putting principals back into practice: an evaluation of a re-entry course for vocationally trained doctors. Br J Gen Pract. 1997:47:819-22.

68. Harrison J, Redpath L. Career Start in County Durham. In: GP Tomorrow. Abingdon: Radcliffe Medical Press; 2002. p. 59-74.

69. Delacourt L, Savage R. South London VTA Scheme seven years on. In: GP Tommorow. Harrison J and Van Zwanberg T editors. Abingdon: Radcliffe Medical Press; 2002. p. 105-114.

70. Felix H, Shepherd J, Stewart MK. Recruitment of rural health care providers: a regional recruiter strategy. J Rural Health. 2003;19(Suppl):340-6.

71. Maclsaac P, Snowdon T, Thompson R, Wilde T. Case management: a model for the recruitment of rural general practitioners. Aust J Rural Health. 2000:8:111-5.

72. Viscomi M, Larkins S, Gupta TS. Recruitment and retention of general practitioners in rural Canada and Australia: a review of the literature. Can J Rural Med. 2013;18:13-23.

73. Dolea C, Stormont L, Braichet JM. Evaluated strategies to increase attraction and retention of health workers in remote and rural areas. Bull World Health Organ. 2010;88:379-85

74. The Future Primary Care Workforce : creating teams for tomorrow. Report of the Primary Care Workforce Commission. London: HEE; 2015.

75. The UK Foundation Programme Office. National F2 Career Destination Report 2015. http://www.foundationprogramme.nhs.uk/pages/home/ keydocs. Accessed 5 Jun 2015. 